\title{
AS PERCEPÇÕES DA COMUNIDADE ESCOLAR SOBRE A COLETA SELETIVA EM UMA INSTITUIÇÃO DE ENSINO SUPERIOR PRIVADA
}

\author{
Roseli dos Santos Celestino ${ }^{1}$ \\ Reysila Rossi Lima Rodrigues de Carvalho² \\ Janaína Simone Silva de Assis $^{3}$ \\ Israel Francisco Petronetto de Almeida ${ }^{4}$ \\ Janilza Dias Moreira ${ }^{5}$ \\ Desirré Gonçalves Raggi6
}

Resumo: O objetivo do presente trabalho foi verificar o programa de coleta seletiva de uma instituição de curso superior privada na região de São Mateus. Em relação aos procedimentos metodológicos, a pesquisa foi de cunho quantiqualitativo de caráter exploratório, por meio de entrevistas estruturadas com gestores, alunos e funcionários, totalizaram 162 sujeitos. Os dados coletados evidenciaram que a instituição de ensino não possui coleta seletiva/triagem dos resíduos sólidos assim como a inexistência de um programa de Educação Ambiental para os alunos. Como consequência, os entrevistados demonstraram possuir pouco conhecimento sobre a correta separação do lixo e o seu descarte. Espera-se que os dados coletados nesta pesquisa sirvam de referência para que a faculdade elabore um programa de Educação Ambiental, incluindo a coleta seletiva visando à transformação da realidade local.

Palavras-chave: Lixo; Comunidade Escolar; Meio Ambiente; Educação.

\footnotetext{
${ }^{1}$ Prefeitura de São Mateus. E-mail: licelestino@hotmail.com. Link para o Lattes: http://lattes.cnpq.br/3051974578839575

2 Prefeitura de São Mateus. E-mail: reysilarossilima1@gmail.com. Link para o Lattes: http://lattes.cnpq.br/8319079554598258

${ }^{3}$ Prefeitura de São Mateus. E-mail: janaina.silva.assis@hotmail.com. Link para o Lattes: http://lattes.cnpq.br/5307324526565597

${ }^{4}$ Faculdade Vale do Cricaré. E-mail: petronettoconsultoria@outlook.com. Link para o Lattes: http://lattes.cnpq.br/3630712259014122

5 Prefeitura de São Mateus. E-mail: janilzadiasmoreira@hotmail.com.

${ }^{6}$ Faculdade Vale do Cricaré. E-mail: desireeraggi@yahoo.com.br.

Link para o Lattes: http://lattes.cnpq.br/5840351062122519
} 
Abstract: The objective of the present work was to verify the selective collection program of a private higher education institution, in the region of São Mateus. Regarding the methodological procedures, the research was of a quantitative and qualitative nature of an exploratory character, through structured interviews with managers, students and employees, totaling 162 subjects. The data collected showed that the educational institution does not have selective collection / sorting of solid waste as well as the lack of an environmental education program for students. As a consequence, respondents demonstrated little knowledge about the correct separation of waste and its disposal. It is hoped that the data collected in this research will serve as a reference for the college to develop an environmental education program, including selective collection aimed at transforming the local reality.

Keywords: Trash; School Community; Environment; Education.

\section{Introdução}

Conceituar meio ambiente significa discutir sobre a própria espécie humana que desde o início da humanidade interage com a natureza e o contexto histórico de forma muito intensa. Essa interação entre o homem e a natureza foi conquistada com muito esforço, e, consequentemente, acarretaram benefícios e malefícios (SILVA et al., 2019). Conforme Silva, Araújo e Corte (2020), na contemporaneidade, a humanidade sofre consequências provocadas por ações inadequadas. Não é difícil perceber que há muito tempo o planeta pede socorro, principalmente após a Revolução Industrial o mundo passou por mudanças significativas para produzir os bens de consumo. $O$ estímulo à produção para aumento de lucros promovido pelo sistema capitalista alterou o padrão de comportamento humano que gerou novos modos de consumo, alterando substancialmente as paisagens naturais à medida que provocavam impactos de destruição dos recursos do planeta.

Nesse sentido, é salutar repensar posturas que visem à sustentabilidade ambiental, como alude Butzke (2006), pois o planeta está caminhando para a extenuação dos recursos naturais, tendo em vista os elevados níveis de poluição, perda na biodiversidade e escassez da água. Somados a isso, a ausência de destinação correta para o lixo gerado nos ambientes domésticos e nas instituições sociais. Assim Chierrito-Arruda et al. (2018) evidenciam que as ações individuais e políticas sejam tomadas no sentido de um comportamento pró-ambiental.

Nesse contexto, a educação se destaca como agente de transformação de modelos arquétipos erroneamente aceitos e praticados pela sociedade que ainda destrói o meio ambiente. Mais especificamente, a Educação Ambiental se revela como ferramenta essencial de conscientização de pessoas, de mudanças de valores e de hábitos em relação ao planeta. Nessa perspectiva, a Constituição Federal Brasileira (1988) em seu art. 225 visando à saúde e qualidade de vida, preconiza que todos os cidadãos têm direito ao meio 
ambiente ecologicamente equilibrado, cabendo ao poder público à sua preservação para as gerações presentes e futuras.

$\mathrm{Na}$ onda de destruição dos recursos, a ausência de práticas de coleta seletiva implica em um agravamento dos problemas ambientais (CHIERRITOARRUDA et al. 2018). Assim, alguns entes sociais apontam a coleta seletiva como uma das alternativas para novas mudanças. Os resíduos sólidos quando não tratados de forma correta transformam-se em problemas ambientais para 0 planeta e a saúde da população (MARQUES et al., 2020). No Brasil, essa discussão foi paulatinamente ganhando destaque por volta dos anos 80 , inicialmente nos ambientes domésticos, e subsequentemente foram surgindo às associações e cooperativas de coleta seletiva. A separação do lixo era realizada de acordo com o material rejeitado. O descarte e o rejeito passariam por um processo de reorganização com 0 melhor aproveitamento desse material (ALMEIDA, 2020).

Assim surgiu a pedagogia dos 3 R's, que significam: reduzir, reutilizar e reciclar (STEPHANOU, 2013), num evento realizado na década de 90 e que tinha como objetivo promover ações para minimizar o crescente consumo da população, sem esquecer, que esse consumo exagerado é exigência do capitalismo, da oferta e da procura. Esse tratado vai de encontro com uma frase famosa de Lavoisier "Na vida nada se cria, nada se perde, tudo se transforma". É preciso reduzir, reutilizar e reciclar, são princípios norteadores dessa nova política.

A reciclagem, nos últimos anos, tem sido apontada como solução para destinação do lixo. A regra é reciclar e reutilizar. Vários são os projetos que incluem a coleta seletiva, sem preocupação de sensibilizar o cidadão para reduzir o consumismo e a produção do lixo na natureza. Convergindo com os estudos de Rodrigues e Cavinato (1997), os autores trazem esta abordagem, no sentido de reciclar, e que os materiais descartados sejam transformados em matéria-prima e na fabricação de novos produtos.

Contudo, ainda não se observam na totalidade das instituições públicas e privadas uma estrutura para a correta separação dos resíduos produzidos em seu interior (ALMEIDA, 2020). Muitas vezes, as escolas até dispõem de coletores de resíduos com as cores indicadas, porém grande parte dos alunos e professores desconhece o significado das cores dos recipientes e, comumente, o lixo é jogado de forma desorganizada, sem qualquer separação. Almeida (2020) destaca que existem estabelecimentos de ensino que fazem a coleta, e quando passa o caminhão do lixo não há qualquer seleção, e os resíduos novamente são misturados e encaminhados para lixões. Nesse contexto, percebe-se que a Educação Ambiental exige trabalho árduo, contínuo e com elevado nível de complexidade.

Além da coleta seletiva, são necessárias atividades que visem à conscientização ambiental no intuito de reduzir o consumo desnecessário de todos os segmentos de uma comunidade escolar. É de fundamental relevância a informação e formação de pessoas para que se sintam sensibilizadas frente 
aos agravos ambientais. A Educação Ambiental faz com que pessoas, numa perspectiva coletiva, assumam atitudes de conservação do meio ambiente e busquem soluções sustentáveis de produção e consumo, devendo ser iniciada logo na infância e permanecer durante toda a vida do indivíduo para diminuir a degradação do meio ambiente (DAMIANO et al., 2020). Além disso, é importante que as comunidades se mobilizem e exijam políticas públicas mais precisas em âmbitos municipais, estaduais e federais, que apontem para a correta destinação do lixo produzido nos diversos núcleos sociais.

Nesse aspecto, esta pesquisa objetivou verificar o programa de coleta seletiva de uma instituição de curso superior privada na região de São Mateus no Espírito Santo, analisando as percepções da comunidade escolar sobre como é feita a destinação dos resíduos sólidos no cotidiano da instituição. Concorrem com o seguinte objetivo específico, analisar se há um sistema de coleta seletiva dentro da faculdade, que estão dispostas no pátio, nas salas de aula e na cantina.

\section{Metodologia}

Este estudo é de cunho quanti-qualitativo de caráter exploratório. Em relação aos procedimentos metodológicos, a pesquisa foi desenvolvida por meio de entrevistas estruturadas, junto aos gestores, alunos e funcionários da instituição universitária privada, cuja amostra estratificada contemplou 140 alunos dos 14 cursos de graduação da faculdade, variando de cinco a oito de cada curso. Também fizeram parte da investigação, dez funcionários do corpo administrativo, dois diretores e dez professores. Todos estes sujeitos foram escolhidos de forma aleatória, exceto os diretores, devido à natureza da função, foi elaborado um termo de consentimento para os participantes da pesquisa, resguardando com o devido decoro a identidade dos mesmos.

Este trabalho é resultado de uma pesquisa realizada em uma instituição particular de ensino superior, localizada no município de São Mateus, no Espírito Santo, onde foram investigados três segmentos da comunidade escolar: gestores, alunos e funcionários administrativos. A faculdade oferta 14 cursos de graduação, 14 cursos de especialização e um mestrado profissional. São mais de 2000 alunos estudando em três turnos e finais de semana. A estrutura física é ampla, com novas salas sendo construídas, para atender a demanda da comunidade do município e do entorno.

A faculdade tem apenas um contêiner de coleta seletiva para todo o prédio. Há várias lixeiras distribuídas em salas, corredores e pátios, porém não há diferenciação de cores e recebem todo tipo de resíduo. O lixo produzido vai para o lixão da cidade, localizado no bairro Liberdade. Não existe doação e venda de resíduos sólidos. As palestras sobre Educação Ambiental são esporádicas, embora a instituição contemple a disciplina de Educação Ambiental e faz parte do currículo de diversos cursos. 
Foram elaborados três diferentes roteiros de perguntas, sendo um para cada segmento de público. As entrevistas foram transcritas e os dados foram tabulados de forma quantitativa. Rosa e Arnoldi (2006) evidenciam que a entrevista é um mecanismo de coleta de dados, utilizada de maneira congruente, sendo previamente determinada pelo pesquisador. Ela garante com maior eficácia a sistematização de informações, de forma completa e com menos tempo.

Os dados das entrevistas foram sintetizados em gráficos com o objetivo de evidenciar a coleta seletiva efetivada na instituição e posterior análise.

Tjora (2006), explica que as observações e as entrevistas são procedimentos que se interagem, tendo em vista que a entrevista coordena o pesquisador para a observação, ao passo que as observações alvitram os aprofundamentos basilares para as entrevistas.

\section{Marcos regulatórios básicos: breves considerações}

Quando se fala em meio ambiente, não há como desvincular a ideia de preservação, uma vez que com o desenvolvimento econômico e industrial a devastação dos recursos naturais aconteceu com a mesma proporção ou até mesmo com mais intensidade, levando-se em conta que no decorrer do século XX houve o agigantamento do sistema econômico mundial. Duarte (2006) avulta que, devido aos avanços tecnológicos resultou em impactos desastrosos ao planeta.

Segundo o art. 225 da Constituição de 1988, todos têm direito ao meio ambiente ecologicamente equilibrado, sendo um fator preponderante à qualidade de vida das pessoas, impondo-se ao Poder Público e à coletividade o dever de defendê-lo e preservá-lo para as presentes e futuras gerações. Nesse sentido, para asseverar a efetividade desse direito, é de competência de os órgãos públicos proporcionarem a Educação Ambiental em todas as etapas de ensino e a sensibilização de todos, gerando desta forma a salvaguarda do planeta (BRASIL,1988).

A educação ecológica deve ocupar um lugar constitutivo da formação humana, pois educação se constitui ao longo do tempo e da vida. Desta feita, alguns questionamentos precisam ser realizados tais como: Que tipo de ser humano pretende-se formar com a Educação Ambiental?

O mundo está com a atenção voltada para essa temática. Profusos acordos e tratados referentes à preservação ambiental aconteceram ao longo do tempo, a título de exemplo, a Conferência de Estocolmo ocorrida em 1972, organizada pelas Nações Unidas, ganhando notabilidade como o primeiro evento integralmente ambiental que serviu como alerta para a sociedade mundial sobre os problemas ambientais ocasionados pela atividade humana. Como resultado da Conferência, foi instituída a Convenção da Declaração relativo ao Meio Ambiente Humano na ECO-92, alicerçado na anuência de 191 países, no qual estes deveriam designar $0,7 \%$ do Produto Interno Bruto (PIB) 
para os países pobres, que se comprometeram com a preservação ambiental e a biodiversidade (JUS.COM.BR, 2011).

No Japão, em 1997, sucedeu a Conferência das Nações Unidas com relação às mudanças do clima, na qual foi estruturado o Protocolo de Kyoto com a finalidade de diminuir a emissão de gases, e, consequentemente, minorar o efeito estufa. Em Johannesburgo, no ano de 2002 foi realizada a Cúpula Mundial sobre Desenvolvimento Sustentável (CMDS), comumente chamada Rio+10, a partir da necessidade de a humanidade chegar a um consenso sobre a redução do grau de interferência antrópica (humana) sobre o meio ambiente, visando a conter processos destrutivos que resultariam na impossibilidade da vida humana em determinados lugares ou mesmo no mundo todo (DINIZ, 2011).

A Educação Ambiental permeia todos os eventos que trataram os problemas ambientais, haja vista que é o ponto de partida para a construção de uma nova identidade centrada nos princípios da participação coletiva, democrática, com visão de totalidade que abarca as múltiplas dimensões da interação homem/meio ambiente. Tais preceitos são basilares nas ações pedagógicas interdisciplinares que visem ao debate e às reflexões sobre as ações cotidianas dos sujeitos que compõem as instituições sociais (BECIGO; MENDES; ARAÚJO, 2018).

Desse modo, espera-se que os indivíduos adquiram amadurecimento de sua consciência ambiental, tornem-se formadores de opinião e não apenas atuem para cumprir normas e regras, mas sim como agentes participativos nas ações implementadas nos ambientes em que vivem. Assim Bigotto (2008, p. 29) patenteia que "uma das principais causas da problemática ambiental foi atribuída à ciência moderna e à revolução industrial, que fizeram a distinção das ciências, o fracionamento do conhecimento e a compartimentalização da realidade em campos disciplinares confinados [...]". Nesse sentido, as instituições escolares precisam rever seus currículos para que possam integrar as diferentes áreas do conhecimento e contribuir com a formação de indivíduos dotados de pensamento crítico, que questionem a realidade com capacidade de assumir ações pessoais e sociais no sentido de possibilitar as transformações nas relações sociais, como sugere Baquero (2012).

\section{A importância da Educação Ambiental nas escolas}

O ensino formal tem enfrentado grandes desafios no tocante à Educação Ambiental, no ano de 1997 o Ministério da Educação elaborou uma nova proposta curricular denominada Parâmetros Curriculares Nacionais (PCN's), onde o meio ambiente passou a ser tema transversal nos currículos básicos do ensino fundamental, isto é, de $1^{\text {a }}$ a $8^{\text {a }}$ séries (MEDEIROS et al., 2011). Assim, Morin (2004) aponta que a problemática educacional está correlacionada ao desmembramento do ensino, ou seja, a incapacidade de articulação entre os saberes. 
Nesse sentido Souza (2020, p. 117) aponta que "[...] todos os povos da terra devem sentir responsáveis pelo futuro do planeta suscitando ações interiores que desencadeiem um planeta sustentável. O diálogo dentro da escola e as ações coletivas têm sido referenciados como fortes aliados por uma proposta sustentável".

Ao se falar em sustentabilidade e Educação Ambiental, a escola torna-se uma grande aliada do meio ambiente, visto que é nela que as ideias devem ser lançadas nas crianças e nos adolescentes. Envolver os estudantes nessa temática é permitir que a reflexão juntamente com as ações de preservação, responsabilidade e compromisso inicie desde cedo. Para isso, é importante que toda a comunidade escolar esteja envolvida para que as ações possam ser constantes e progressivas (BECIGO; MENDES; ARAÚJJ, 2018). Nesse sentido, é tarefa da escola promover debates, ações coletivas, visitas a parques e instituições que cuidam e preservam o meio ambiente, realizar projetos também pode ser uma excelente iniciativa para promover a Educação Ambiental. Debater sobre Educação Ambiental não deve ser entendido apenas como compromisso da educação formal, isto é, da escola, e sim de toda a sociedade que precisa se responsabilizar pelas ações que dizem respeito à preservação do meio ambiente. Cuidar do planeta de forma sustentável com equilíbrio é tarefa de todos (SOUZA, 2020).

Convergindo Santos, Costa e Santos (2019, p. 29) versam que:

Ações de Educação Ambiental tornam-se uma ótima maneira para incentivar alunos a fazerem o gerenciamento correto no âmbito escolar, visto que muitas escolas lidam constantemente com o mau gerenciamento dos resíduos sólidos que são produzidos durante os horários de funcionamento. Parte desses problemas está relacionada à ausência de ações, e medidas de Educação Ambiental por parte dos professores e equipe de gestão, que poderiam ser minimizados com a adoção de estratégias eficazes, visando à mudança de comportamento no âmbito escolar. 
bojo, a coleta seletiva se destaca como possibilidade educativa importante para a criação de hábitos e atitudes que constituirão a cultura pautada nos cuidados ambientais.

\section{A coleta seletiva}

Diante dos impactos ambientais urge a necessidade de se pensar em alternativas para minimizar os agravos ao planeta, nesse caso a coleta seletiva torna-se imprescindível para um meio ambiente ecologicamente correto. Ao falar de coleta seletiva é primordial abordar sobre a disposição dos resíduos sólidos, uma vez que ao se tratar de meio ambiente, esse é o maior desafio dos gestores municipais, estaduais e federais, pois a cada dia se consome mais e se produz mais resíduos, isso se deve a fatores como o hábito cultural da população, por outro lado faltam políticas públicas voltadas para a destinação correta do lixo (ALMEIDA, 2020). De acordo com Silva et al. (2019, p. 262):

Novos padrões de consumo e mudanças sociais vinculadas ao poder de compra intensificam o acúmulo de lixo na natureza. A disposição de resíduos sólidos urbanos de maneira irregular configura problemas ambientais de grandes proporções, e os impactos oriundos dessa problemática já se encontram sob a perspectiva do visível.

Esses resíduos produzidos pela sociedade consumista precisam ter um destino adequado e para tal é fundamental que haja coleta seletiva desses materiais para posteriormente serem reutilizados em forma de um produto novo (ALMEIDA, 2020). Nesse sentido, Santos, Costa e Santos (2019, p. 27) destacam que "o gerenciamento de resíduos sólidos envolve a coleta, transporte, tratamento e destinação final ambientalmente adequada, [...] a gestão correta ainda é escassa, uma vez que o poder público não incentiva o seu cumprimento integral [...]". Somente com separação correta dos resíduos produzidos, os processos de reuso e reciclagem seriam possibilitados.

No que diz respeito ao consumismo Godecke; Naime; Figueiredo (2012, p. 1701) relatam que os aspectos:

[...] econômicos e culturais se associam à questão demográfica para acelerar o ritmo da deterioração dos recursos ambientais. A quantidade de resíduos sólidos produzidos pelas populações guarda relação não só com o nível de riqueza, refletido na capacidade econômica para consumir, mas também com os valores e hábitos de vida, determinantes do grau de disposição para a realização do consumo [...]. 
A partir dessa citação, percebe-se que uma das causas da degradação do meio ambiente advém dos aspectos econômicos e culturais agravado pelo aumento da população. Sabe-se que através das ciências que estudam o comportamento humano que a humanidade foi conquistando pouco a pouco o seu espaço e, ao mesmo tempo, alcançando os meios de sua próp ria subsistência com o auxílio da natureza. Em contrapartida, esse progresso trouxe resultados nefastos devido às novas necessidades que o ser humano foi adquirindo ao longo do tempo. Outro ponto importante dessa temática, tem relação com os valores e hábitos que a sociedade hodierna granjeou, procurando a sua satisfação pessoal a qualquer custo. Comprar e ter tornaram-se ações primordiais no cotidiano dessa sociedade capitalista, trazendo assim malefícios de diversas ordens, prejudicando até 0 meio ambiente.

Nesse sentido, cabe à sociedade, adotar novas atitudes e novos hábitos com o objetivo de diminuir o consumismo exagerado. Para que as mudanças possam ocorrer, é necessária a adoção de medidas que abrange tanto no aspecto individual quanto no aspecto coletivo, pois é importante que cada um faça a sua parte em relação à minimização na geração de resíduos sólidos. Acredita-se que não será uma tarefa fácil de ser resolvida, mas é preciso começar.

\section{Reeducação, reuso e reciclagem}

Pode-se começar com a definição de conceitos dos 3Rs, que são: reduzir, reutilizar e reciclar. Reduzir entende-se no sentido de minorar o volume de lixo produzido, consumindo o essencial, consequentemente, evitando o desperdício. Reutilizar é entendido como aproveitar este material que a priori não apresenta nenhuma utilidade, o que é um engano, considerando que repetidas vezes são descartados por serem considerados inúteis, ou seja, o material descartado agora ganha um novo aspecto e também utilidade (SILVA et al., 2004).

O processo de reciclagem, que também é uma forma de reusar o lixo, é considerado mais indicado devido aos gastos de energia para sua transformação em um novo produto. Se houvesse uma prevenção na fabricação desses produtos utilizando material que fosse degradável e se o consumo fosse mais consciente, os impactos ambientais seriam minimizados (LIMA et al., 2013).

O consumismo do século atual tem sido uma frente poderosa no que diz respeito à produção de resíduos sólidos, logo essa troca recorrente de bens de consumo tem gerado um aumento gradativo de Resíduos Sólidos Urbanos (RSU). Segundo Queiroz e Vieira (2018), conforme aumenta à expansão demográfica, a produção de resíduos no planeta também aumenta, pois quanto maior o número de pessoas, maior o número de artigos consumidos e maiores serão também o número de resíduos que serão descartados em forma de resíduos sólidos. Esse aumento tem gerado preocupação para os gestores das 
grandes cidades, principalmente por não existir um local ideal para o depósito desses resíduos. Partindo desse pressuposto, Almeida (2020) e Lima et al. (2013) destacam que são imprescindíveis técnicas, investimentos e estratégias que diminuam consideravelmente o descarte dos RSU.

Algumas atitudes no ambiente doméstico, social e até mesmo no ambiente escolar podem gerar menos impacto ao meio ambiente, uma delas consiste em eliminar o uso de canudinhos, copos descartáveis, guardanapos de papel, ou caso for necessário usá-los com parcimônia e é fundamental que haja um acondicionamento adequado, permitindo sua separação para posterior reciclagem a fim de propiciar a formação de uma cultura ambiental, que possa contribuir com a sustentabilidade. Nessa perspectiva, Medeiros et al. (2011, p. 15) defendem que a escola venha a ser "Um local onde todos os indivíduos se preocupem com a limpeza, descartando o lixo no recipiente correto para reutilização do mesmo para o mundo".

\section{Discussões e resultados}

Nessa etapa serão apresentados os resultados coletados na respectiva instituição, primeiramente serão evidenciados os resultados coletados com os alunos da mesma, a análise de resultados será dividida por segmento de sujeitos.

\section{As opiniões dos alunos}

O Gráfico 1 a seguir representa a idade dos alunos entrevistados. Totalizaram 115 discentes dos seguintes cursos: Administração, Análise de Sistema, Ciências Contábeis, Direito, Educação Física, Enfermagem, Engenharia de Produção, Engenharia Mecânica, Fisioterapia, Pedagogia, História e Psicologia.

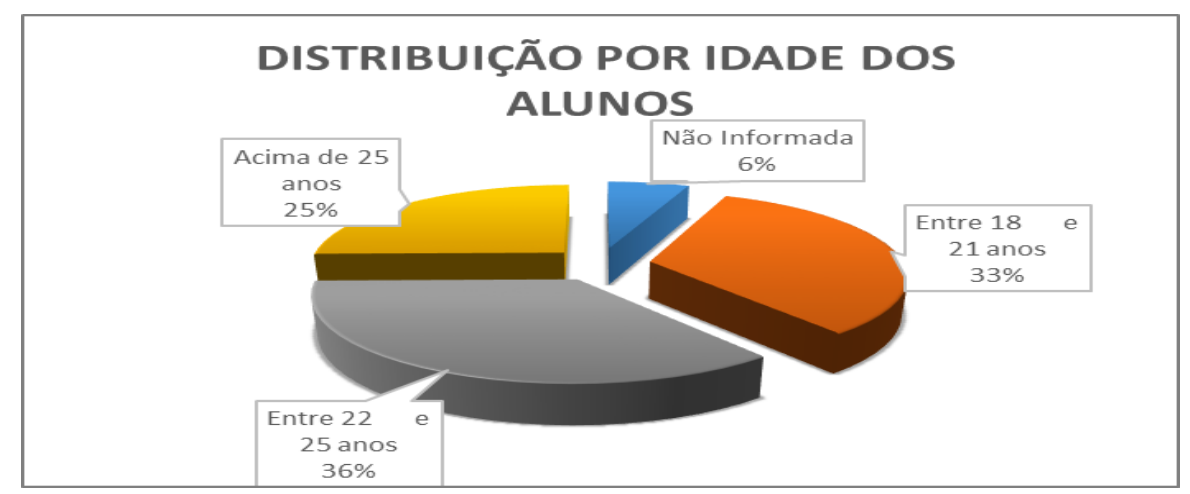

Gráfico 1: Idade dos alunos. Fonte: Construído pelos autores, 2018.

O Gráfico 1 informa que a maioria dos alunos da instituição são jovens de 22 a 25 anos, sendo que o ideal seria de 18 a 21 anos, quando os mesmos 
concluem o ensino médio. O público acima de 25 anos também é considerável e representa cerca de $25 \%$. Isso significa que são alunos mais maduros que entraram tardiamente na faculdade, provavelmente optando, num primeiro momento, pelo mercado de trabalho, até mesmo para custear os cursos universitários.

De acordo com o Gráfico 2, o público da pesquisa contemplou alunos dos seguintes cursos: Pedagogia 13\%, Ciências Contábeis 12\%, Administração $12 \%$, totalizando $37 \%$ do público. A disparidade existente entre o número de entrevista se deu devido a muitos alunos se negarem a participar da mesma.

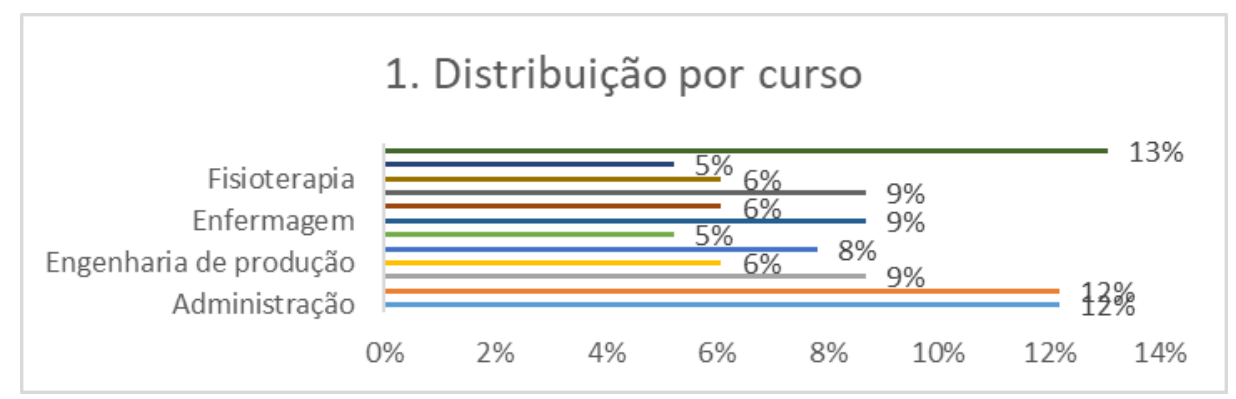

Gráfico 2: Distribuição por curso. Fonte: Construído pelos autores, 2018.

Os dados do Gráfico 3 demonstram as opiniões sobre os modos de separação do lixo pela instituição, se consideram adequada ou não. Os resultados ficaram tecnicamente empatados: $47 \%$ responderam não e $45 \%$ sim, considerando os $8 \%$ que não souberam responder. Os dados refletem a falta de informação dos discentes sobre coleta seletiva, e preocupante, levando-se em conta o nível de escolaridade e as falhas da instituição em não dispor de coletores adequados para fazerem a separação correta.

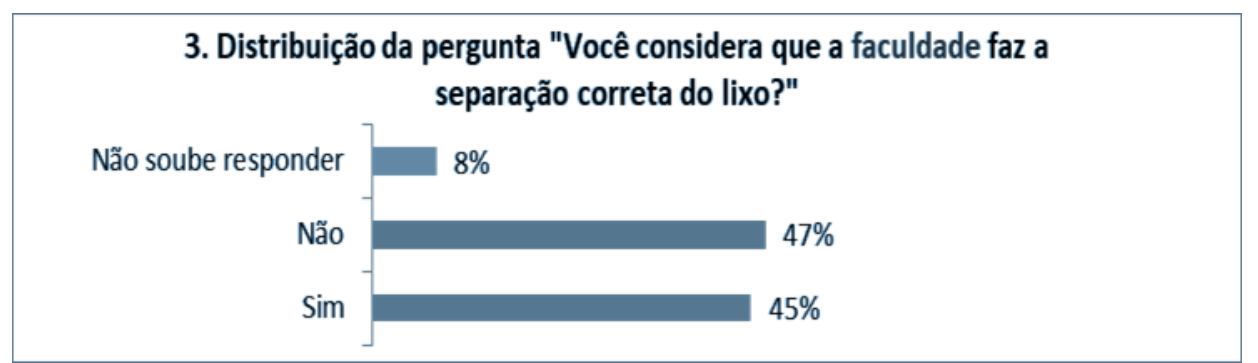

Gráfico 3: Você considera que a faculdade faz a separação correta do lixo?

Fonte: Construído pelos autores, 2018. 
entende que fazer a separação correta do lixo minimiza os impactos ambientais.

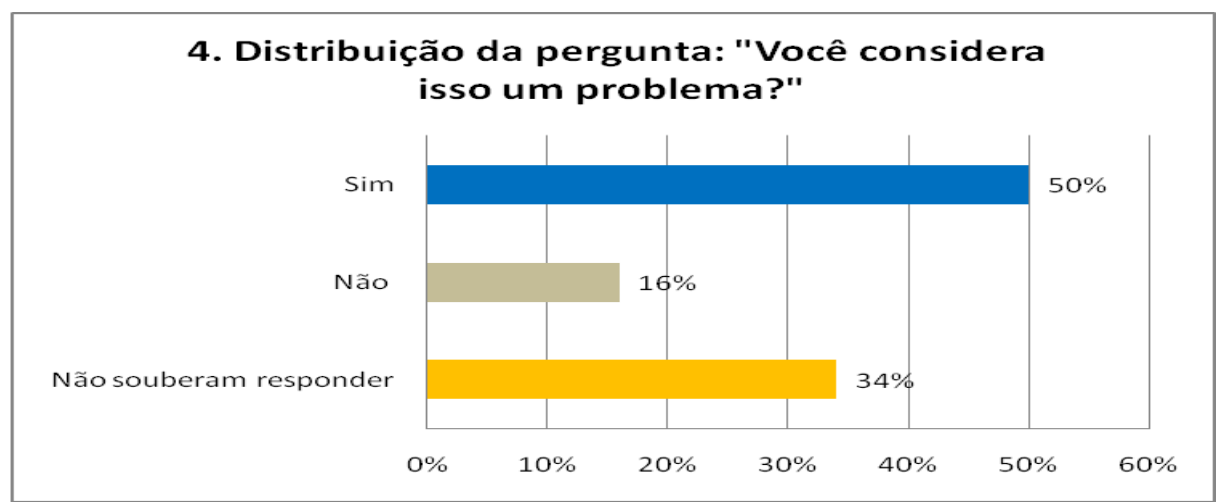

Gráfico 4: Você considera isso um problema? Fonte: Construído pelos autores, 2018.

Não considerar como um agravante que a destinação do lixo seja realizada de forma correta torna-se preocupante, haja vista que na segunda metade do século $\mathrm{XX}$, houve um agigantamento populacional, além do desenvolvimento tecnológico. Nesse ínterim, os hábitos foram se transmudando e a geração de resíduos sólidos tem se agravado consideravelmente, devido aos modos de consumo da sociedade, principalmente com o sujeito pós-moderno. O Brasil é um país de imensa extensão territorial, o que dificulta ações eficazes no sentido de destinar corretamente o grande volume de lixo produzido pela sociedade (FRÉSCA, 2007).

Com base no Gráfico 5, quanto à sugestão dos alunos, infere-se que houve uma diversidade de sugestões para resolução do problema da destinação correta do lixo, sendo as mais relevantes: $46 \%$ dos alunos responderam que a instituição deveria ofertar a coleta seletiva. Observa-se que no gráfico 3, 45\% responderam que a instituição já separa o lixo corretamente, novamente não havendo um alinhamento de informações, fato que demonstra que eles parecem ainda não ter uma percepção adequada sobre essa problemática ambiental.

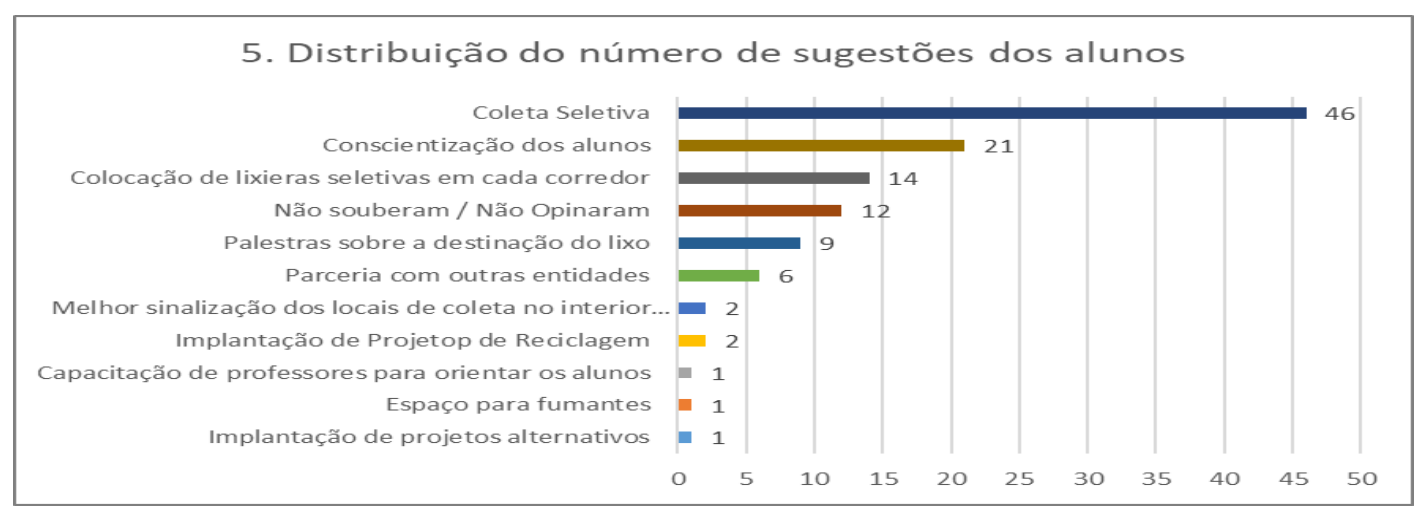

Gráfico 5: Sugestões dos alunos. Fonte: Construído pelos autores, 2018. 


\section{As opiniões da equipe gestora}

A seguir serão apresentados os resultados da equipe gestora da instituição. Com base no Gráfico 6, os diretores admitem que a instituição faz a separação correta do lixo. Entretanto, esses dados divergem das respostas dos alunos, quando $47 \%$ responderam que não faz a separação correta.

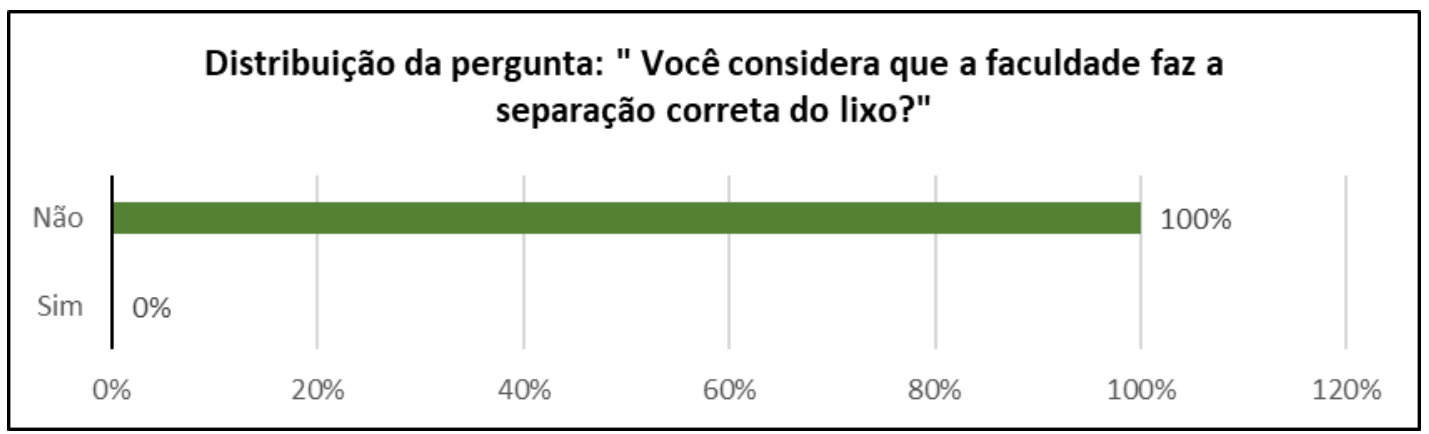

Gráfico 6: Você considera que a faculdade faz a separação correta do lixo?

Fonte: Construído pelos autores, 2018.

Em relação ao Gráfico 7 , a questão se relacionava com a primeira pergunta como um problema. No entanto, observa-se uma divergência nas respostas, pois um dos diretores considera que seja um problema sim e admite que existe muito material desperdiçado. O segundo diretor não considera como um problema, mas como uma questão cultural, por uma obrigação pela essência de a atividade dentro da educação. Está em andamento um projeto nesse sentido para que se possa realizar esse projeto na íntegra. Portanto, reconhece que a faculdade pode melhorar suas ações ambientais quanto à coleta seletiva.

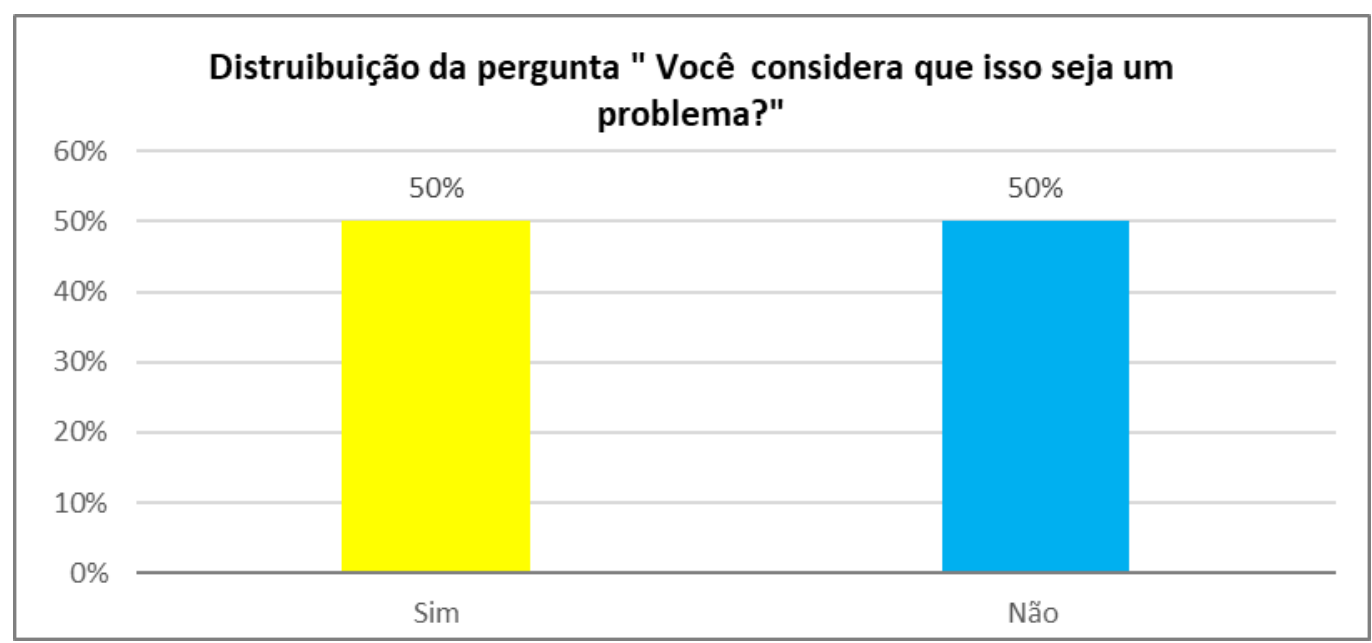

Gráfico 7: Você considera que isso seja um problema?

Fonte: Construído pelos autores, 2018. 
Quando questionados sobre qual solução em relação a essa situação, as respostas foram direcionadas para a existência de "programas, treinamentos, capacitação e conscientização" e na "conclusão de um projeto e a implantação reunindo todos os setores para todos os alunos e uma campanha no sentido de sensibilizar toda a comunidade".

Observa-se, portanto, que a gestão tem conhecimento sobre a problemática em pauta, todavia não existem ações efetivas para mitigá-la.

\section{As opiniões dos funcionários da administração}

Os dados do Gráfico 8 revelam que $52 \%$ desses sujeitos desconhecem a forma correta de coleta e separação do lixo feita pela faculdade. Mas, 31\% responderam que sim, ou seja, consideram que a instituição faz esse trabalho e $17 \%$ não souberam responder. Nesse caso, percebe-se a falta de informação por parte de boa parte dos funcionários em relação ao tema.

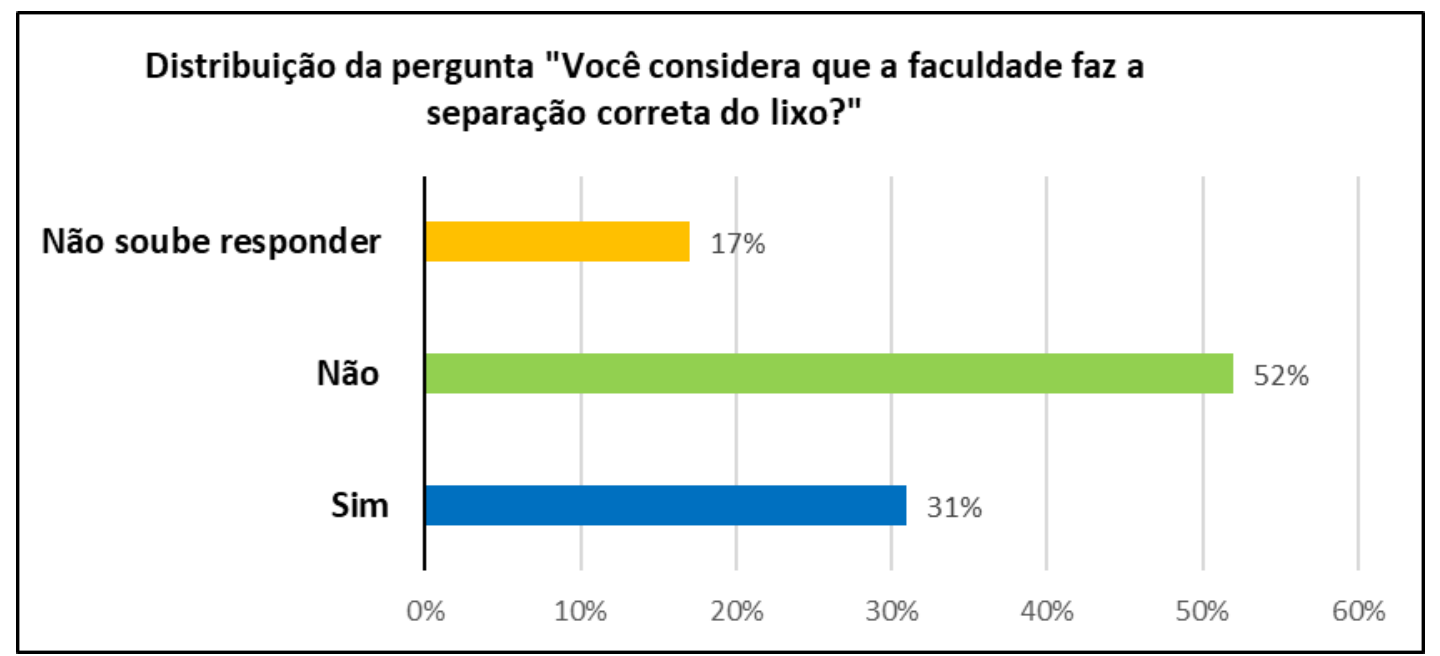

Gráfico 8: Você considera que a faculdade faz a separação correta do lixo?

Fonte: Construído pelos autores, 2018.

Em relação à primeira questão da entrevista, os funcionários foram questionados se seria um problema a separação do lixo, percebe-se no Gráfico 9 que $78 \%$ deles responderam que sim, 15\% responderam que não e apenas $7 \%$ não souberam responder. Os dados mostram que grande parte dos funcionários considera que a faculdade não faz a separação correta do lixo. 


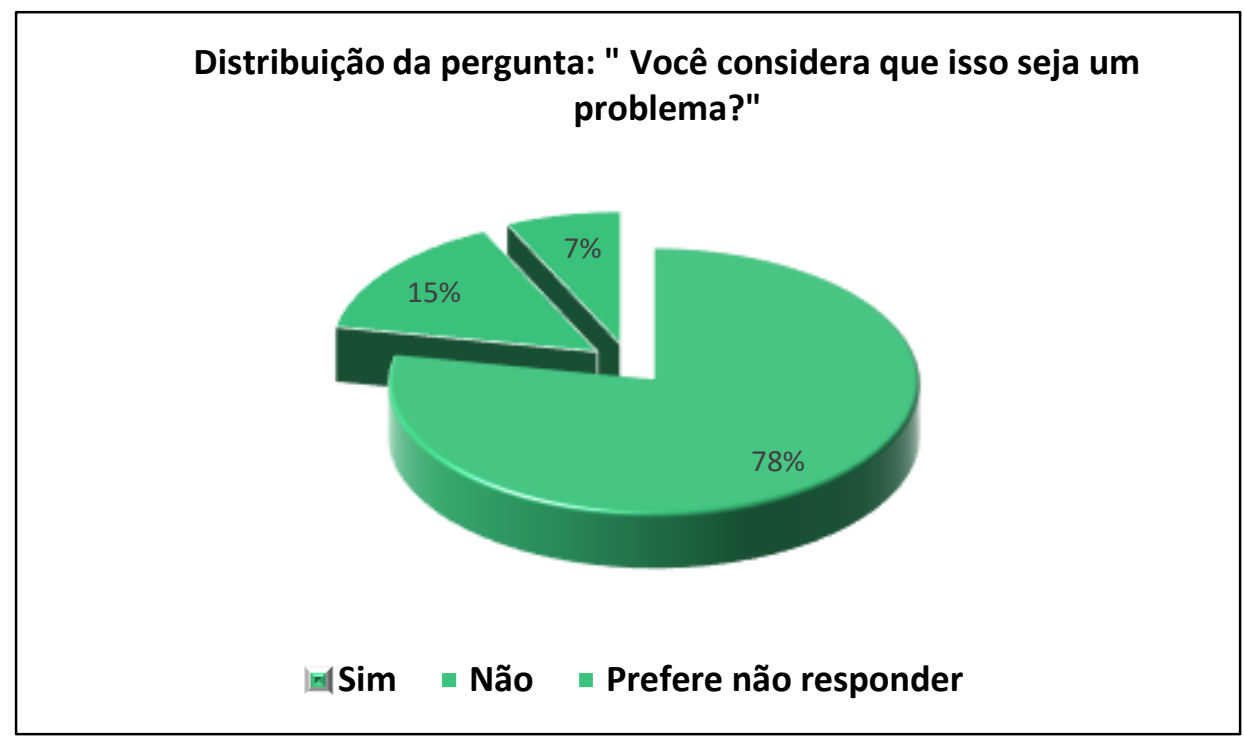

Gráfico 9: Você considera que isso seja um problema? Fonte: Construído pelos autores, 2018.

O Gráfico 10 revela que $84 \%$ dos funcionários consideram que a separação do lixo poderia ser melhorada. Enquanto $8 \%$ responderam que pensam "ser bem difícil" que a instituição faça esse trabalho. Os outros $8 \%$ responderam "talvez", demonstrando certo descrédito. Nota-se, com base nesses resultados que boa parte dos funcionários é mais otimista, acreditando que a instituição pode melhorar a forma de separar o lixo.

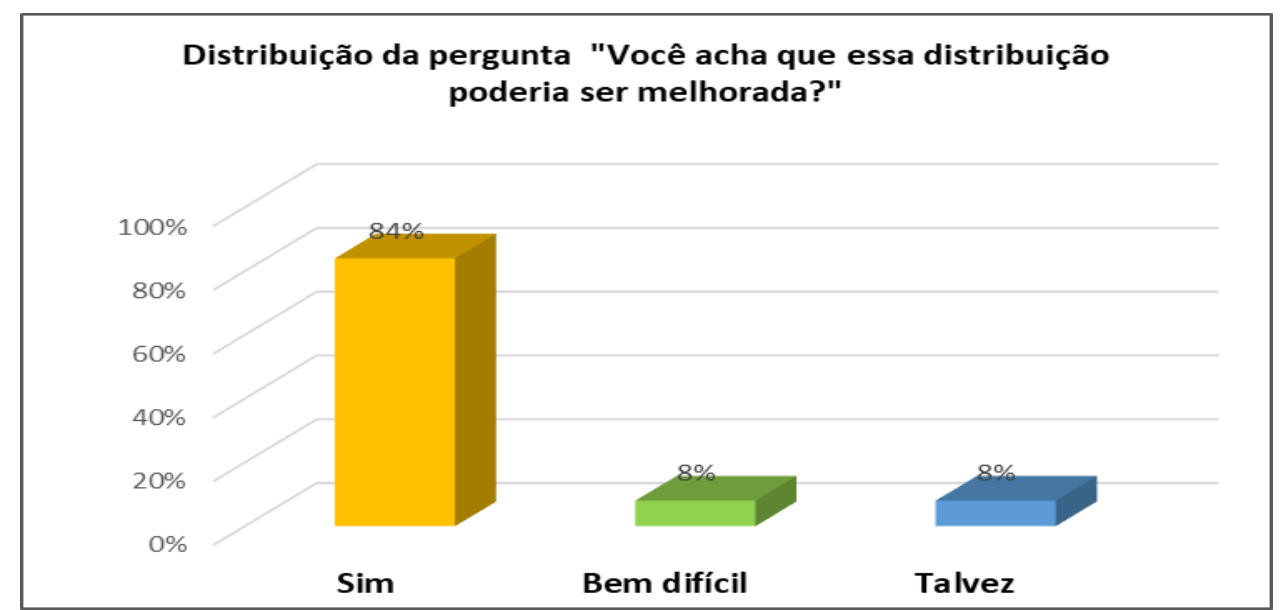

Gráfico 10: Você acha que essa distribuição poderia ser melhorada?

Fonte: Construído pelos autores, 2018.

Levando em conta suas considerações, foram solicitadas sugestões de como melhorar a separação de lixo nas dependências da instituição. As sugestões que predominaram foram (Gráfico 11): a) instalação de mais lixeiras seletivas (23\%); b) campanhas educacionais (23\%). Em segundo lugar, aparece a coleta seletiva com 20\%; 16\% apontaram a necessidade de identificação nas lixeiras, $6 \%$ acreditam serem necessárias políticas públicas 
para sanar o problema. Os demais 3\% de sugestões foram: a) apresentação de projeto para a faculdade, b) parceria com os catadores, reaproveitamento do lixo. Os outros $3 \%$ não souberam responder.

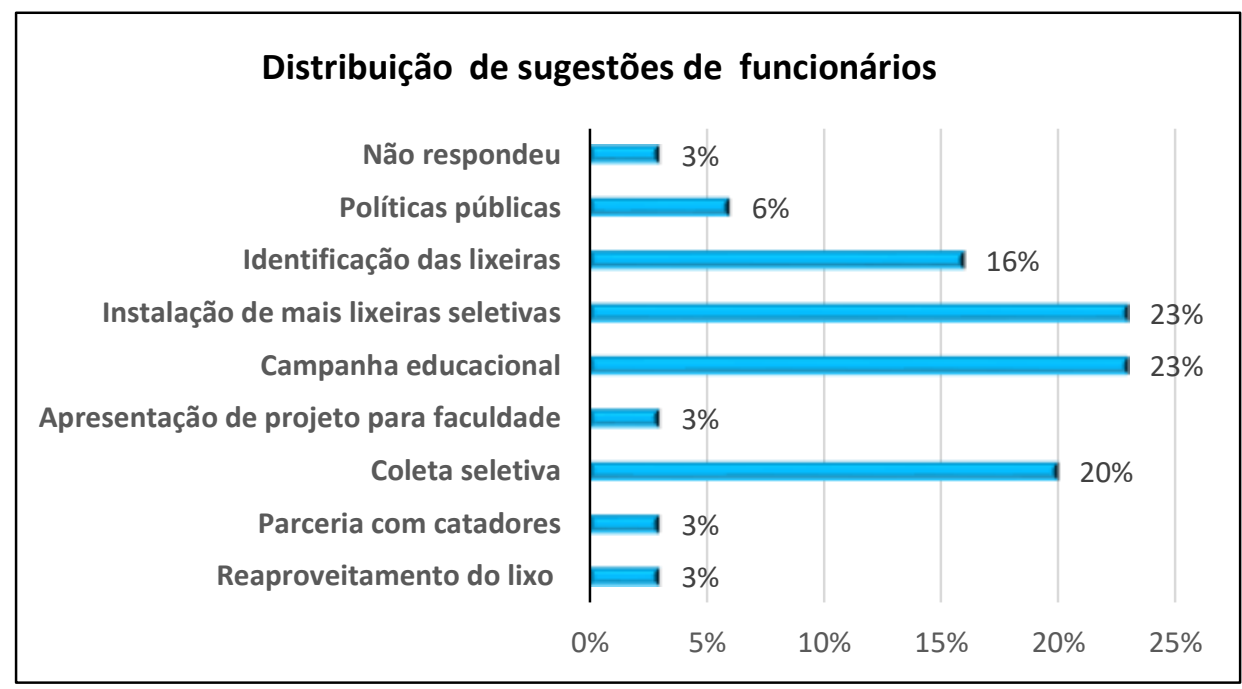

Gráfico 11: Distribuição de sugestões de funcionários. Fonte: Construído pelos autores, 2018.

Observou-se que a maioria dos funcionários declarara que a faculdade não faz a separação correta do lixo, porém ao serem questionados se existem recipientes adequados eles disseram que nunca repararam se estes estão presentes nos espaços que frequentam diariamente. Ao mesmo tempo, declararam que é preciso que haja mais lixeiras adequadas para o descarte correto e identificação nas lixeiras existentes, bem como campanhas de conscientização ambiental nos espaços acadêmicos.

Quanto à visão dos alunos, verificou-se que há falta de informação sobre o assunto para a maioria do público entrevistado. Contudo, esses sujeitos apontaram que a falta de destinação correta para o lixo produzido pela instituição é um problema, demonstrando que os mesmos têm sensibilização ambiental quanto ao destino correto que é dado ao lixo. Os gestores reconhecem a necessidade, porém não demonstraram preocupação em promover mudanças na estrutura.

\section{Considerações finais}

A Educação Ambiental é a base para uma sociedade que se preocupa com as futuras gerações e com a qualidade de vida. Nessa perspectiva, espera-se que em uma instituição de nível superior existam ações de cuidados ambientais, sobretudo como processo de efetivação dos conteúdos propostos pelas próprias disciplinas que constam nos currículos da maioria dos cursos oferecidos pela instituição. 
O resultado da pesquisa mostrou que a instituição corrobora em alguns indicadores, como, por exemplo, a implementação de lixeiras específicas para cada material; porém estas se encontram em um lugar que não privilegia a visualização e como afirmado pela instituição que ela já possui um projeto que ainda não foi colocado em prática.

Os entrevistados disseram que a faculdade deve ter interesse em resolver o problema como afirmam que ela já desenvolve várias ações de reaproveitamento de água da chuva dentre outras ações; porém algumas lacunas precisam ser preenchidas, como a tentativa de estimular capacitações envolvendo todo o corpo discente relacionando à sensibilização ambiental.

Os resultados permitem inferir que existem caminhos a serem percorridos no sentido de implementar ações que viabilizem a prática educativa ambiental. Espera-se que a pesquisa seja um modo de propulsão para o desenvolvimento de novos estudos direcionados à sensibilização do público atingido pela faculdade e que os cuidados ambientais sejam efetivamente efetivados no contexto acadêmico. Ações que tratem da sensibilização da comunidade escolar são substanciais para a proteção do planeta, a fim de contribuir com uma sociedade que saiba valorizar o meio ambiente e tenha posturas que contribuam com a sustentabilidade do planeta.

Tudo isso permite constatar que mudanças ambientais são difíceis, dependem de articulação de diversos segmentos escolares e que a complexidade inerente ao processo educativo requer soluções em longo prazo, e, sobretudo depende da vontade daqueles que detêm o poder.

\section{Referências}

ALMEIDA, I.F.P. Modelo de Gestão da Associação de Catadores de Recicláveis: Um estudo de caso em Pinheiros-ES. Dissertação de Mestrado. Faculdade Vale do Cricaré. 2020. 112p.

BAQUERO, R.V.A. Empoderamento: instrumento de emancipação social? uma discussão conceitual. Revista Debates. Porto Alegre, v. 6, n. 1, p.173187, jan-abr. 2012.

BECIGO, A.P.; MENDES, A.L.R.; ARAÚJO, M.P.M. Revitalização do espaço escolar por meio da mediação pedagógica e da sensibilização ambiental. Revista Científica Intelletto, v. 3, p. 69-81, 2018.

BIGOTTO, A.C. Educação Ambiental e o desenvolvimento de atividades de ensino na escola pública. Dissertação de Mestrado. São Paulo: USP, 2008. Disponível em: <https://www.teses.usp.br/teses/disponiveis/48/48134/tde12062008-152040/publico/DissertacaoAntonioCesarBigotto.pdf>. Acesso em: 01 jan. 2019.

BRASIL. Constituição da República Federativa do Brasil. Brasília, DF, senado. 1988. 
BRASIL. Parâmetros Curriculares Nacionais: introdução aos parâmetros curriculares nacionais / Secretaria de Educação Fundamental. Brasília: MEC/SEF, 1997. 126p.

BUTZKE. A. (Coord). 0 direito ao meio ambiente ecologicamente equilibrado. Caxias do Sul: Educs, 2006.

CHIERRITO-ARRUDA, E. et al. Comportamento pró-ambiental e reciclagem: revisão de literatura e apontamentos para as políticas públicas. Ambient. soc., São Paulo, v. 21, 2018.

CUNHA, C. R. da, NASCIMENTO, C., DALL'ORTO, J. A. C., SILVA, J. G. F. da. A literatura infantil e sua possibilidade de abrir horizontes em relação à Educação Ambiental na primeira infância. Revista Brasileira De Educação Ambiental, 15 (1), 431-441. 2020.

DAMIANO, M.; REZENDE, M. O. O; ARAI, J. N; ICHIBA, R. B. A preservação do meio ambiente: um desafio social, ético e global na educação. Educação Ambiental (Brasil), v. 1, n. 3, p. 10-17, 2020. Acesso em: 30 out. 2020.

DUARTE, M.C.S. Meio Ambiente Sadio: direito fundamental em crise. $1^{\underline{a}}$. ed. (ano 2005), $2^{a}$ tir. Curitiba: Juruá, 2006.

DINIZ, E. (2011). Os resultados da Rio +10 . Revista do departamento de geografia, 15, 31-35.

FRÉSCA, F.R.C. Estudo da geração de resíduos sólidos domiciliares no município de São Carlos, SP, a partir da caracterização física. 2007. Dissertação. Universidade de São Paulo.

GODECKE, M.V.; NAIME, R. H; FIGUEIREDO, J. A. S. O consumismo e a geração de resíduos sólidos urbanos no Brasil. Revista Eletrônica em Gestão, Educação e Tecnologia Ambiental, v. 8, p. 1700-1712, 2012.

JUS.COM.BR. Tratados internacionais de meio ambiente: estatura no ordenamento jurídico brasileiro. 2011. Disponível em: $<$ https://jus.com.br/artigos/19556/tratados-internacionais-de-meio-ambienteestatura-no-ordenamento-juridico-brasileiro >. Acesso em: 02 dez. 2018.

LIMA, A. M. et al. Gestão de Resíduos Sólidos: A percepção da população de Tangará da Serra-MT em relação a coleta seletiva. Anais do IX Congresso Nacional de excelência em gestão, 2013.

MARQUES, J. G. C.; TAVARES, C. M; ALMEIDA, A. J. G. A; BRANDAO, F. J. R; SOBRAL, M. C. M. Gestão ambiental para sustentabilidade em municípios: um estudo comparativo da aplicação da gestão de resíduos sólidos na Zona da Mata Sul de Pernambuco, Brasil. Revista Geama (on-line), v. 6, p. 51-59, 2020.

MEDEIROS, B.A. et al. A Importância da Educação Ambiental na escola nas séries iniciais. Revista Faculdade Montes Belos, v.4, n.1, set. 2011. 
MORIN, E. A cabeça bem feita: repensar a reforma e reformar o pensamento. Rio de Janeiro: Bertrand Brasil, 2004.

QUEIROZ, N. T.; VIEIRA, E. T. V. Gestão de resíduos sólidos na zona urbana do Município de Varzelândia Rev. Bras. Gest. Amb. Sustent., 2018, v. 5, n. 9, p. 141-156.

RODRIGUES, F.L.; CAVINATO, V.M. Lixo: de onde vem? Para onde vai? Editora Moderna: 1997.

ROSA, M.V.F.P.C.; ARNOLDI, M.A.G.C. A entrevista na pesquisa qualitativa: mecanismos para a validação dos resultados. Belo Horizonte: Autêntica Editora, 2006. 112 p.

SANTOS, A. dos; COSTA, V. S. de O; SANTOS, T. G. Diagnóstico da gestão dos resíduos sólidos em duas unidades escolares. Revista Brasileira de Educação Ambiental, v.14, n.4, pp.25-39. 2019.

SILVA, J.; GOMES, A.; DINIZ, L.; CATÃO, M. Reduzir, REUTILIZAR E RECICLAR- Proposta de Educação Ambiental para o Brejo Paraibano. Anais do Congresso Brasileiro de Extensão Universitária, Belo Horizonte, 2004.

SILVA, R. B; ARAÚJO, M. P. M; LÚCIO, A. P. S; BOF, R. D; SILVA, J. G. F. da. Comportamento pró-ambiental e coleta seletiva: um estudo de caso com moradores de Cariacica (eES). Revista Brasileira De Educação Ambiental, v.14, n.3, pp.260-275. 2019.

SILVA, R.B.; ARAÚJO, M.P.M; CORTE, V.B. A civilização "insustentável" em situação de pandemia de COVID-19: perspectivas de educadores. Revista Brasileira De Educação Ambiental, v.15, n.4, pp.80-94, 2020.

SOUZA, F. R. da S. Educação Ambiental e sustentabilidade: uma intervenção emergente na escola. Revista Brasileira de Educação Ambiental, v.15, n.3, pp.115-121. 2020.

STEPHANOU, J. Gestão de resíduos sólidos: um modelo integrado que gera benefícios econômicos, sociais e ambientais. In: Sustentabilidade: Resultados de Pesquisas do PPGA. Universidade Federal do Rio Grande do Sul. Porto Alegre: UFRS, 2013.

TJORA, A. H. Writing small discoveries: an exploration of fresh observers' observations. Qualitative Research, London, v. 6, n. 4, p. 429-451, 2006. 